\title{
Design Experiment for Leveraging Material Value Coal Ash as Material Mixture of Paving Block
}

\author{
Harris Setyo Fernanto, Djoko Sihono Gabriel \\ Department Industrial Engineering, University of Indonesia, Depok, Indonesia
}

\begin{abstract}
The coal-fired thermal power plant is the main source of coal ash production. Coal ash collected at the bottom of the furnace (boiler) is called coal bottom ash (CBA) and fly ash remaining combustion called coal fly ash (CFA). In Indonesia, the utilization of bottom ash and fly ash generally is still limited to landfill material due to the value of the material too low. The objective of this research is to leverage the value of the utilization of bottom ash and fly ash materials as a mixer of construction industry products. Design of Experiment (DoE) was conducted on paving block product using various experimental factors such as composition of sand, cement, bottom ash, fly ash, and curing period of product. This Design of Experiment (DoE) applied orthogonal array to finding the best mixed compositions that affect the quality of the end result. After it, the proof was performed with a compressive strength test and water absorption test to meet the standard requirements. Testing compressive strength of paving block was done at 7 days, 14 days and 28 days to get the best result.
\end{abstract}

\section{Introduction}

Coal is one of the energy sources used in Indonesia, based on the 2015 estimate of power plants is an industry that ranks first as a coal user as a fuel. Once used in a burning medium (boiler), coal turns into fly ash (fly ash) and ash that falls into the bottom of the combustion chamber (bottom ash) [1]. The old paradigm regarding the utilization of fly ash and bottom ash as landfill hoarders due to too low the value of the material so it is not interesting to use again. Therefore, a new paradigm is considered to consider the leverage of fly ash and bottom ash materials by mixing with other materials to produce better construction products. Both types of materials are classified as waste electricity production, but research utilization is still relatively small. As for existing research, it only shows that fly ash and bottom ash can be used as a substitute material for cement and sand [2], but no one has shown the right experimental method to replace the material in producing the best quality, so research needs to be done to increase the value of performance on the value of economic efficiency.

This research aims to obtain the fly ash \& bottom ash utilization as a paving block industrial product mixer which gives better material value and also seeks evidence of compliance with the Standard National Indonesia (SNI), and then calculates the performance that can be gained from the utilization of fly ash and bottom ash.
This research is limited to the use of fly ash and bottom ash for the construction industry which is used as raw material for paving block product substitution, with explanation of performance test result using laboratory test.

\section{Material and Methods}

\subsection{Materials}

The concrete prepared and tested in this study was composed of Ordinary Portland cement (OPC) ASTM C 150-04a, crushed sand (mixing stone ash \& bangka sand), fly ash and bottom ash. Class F fly ash and Bottom ash were obtained from PT. Indonesia Power, Steam Power Plant Station, Lontar, Indonesia. The properties of CBA \& CFA showed in Table.1 CBA was dried in an oven at a temperature of $110 \mathrm{C}$ for three hours before use to ensure it is in dry state.

Table 1. Properties of fly ash and bottom ASH

\begin{tabular}{|c|c|c|c|c|c|c|c|c|c|c|c|c|}
\hline $\mathrm{FA}$ & $\mathrm{SiO}_{2}$ & $\mathrm{Al}_{2} \mathrm{O}_{3}$ & $\mathrm{Fe}_{2} \mathrm{O}_{3}$ & $\mathrm{TiO}_{2}$ & $\mathrm{CaO}$ & $\mathrm{MgO}$ & $\mathrm{K}_{2} \mathrm{O}$ & $\mathrm{Na}_{2} \mathrm{O}$ & $\mathrm{SO}_{3}$ & $\mathrm{MnO}_{2}$ & $\mathrm{P}_{2} \mathrm{O}_{3}$ & $\mathrm{LOI}$ \\
\hline$\%$ & 34,29 & 16,62 & 15,38 & 0,73 & 18,18 & 7,52 & 1,35 & 2,97 & 1,63 & 0,17 & 0,25 & 0,36 \\
\hline \hline $\mathrm{BA}$ & $\mathrm{SiO}_{2}$ & $\mathrm{Al}_{2} \mathrm{O}_{3}$ & $\mathrm{Fe}_{2} \mathrm{O}_{3}$ & $\mathrm{TiO}_{2}$ & $\mathrm{CaO}$ & $\mathrm{MgO}$ & $\mathrm{K}_{2} 0$ & $\mathrm{Na}_{2} \mathrm{O}$ & $\mathrm{SO}_{3}$ & $\mathrm{MnO}_{2}$ & $\mathrm{LOI}$ \\
\hline$\%$ & 34,39 & 10,02 & 18,41 & 0,65 & 21,16 & 9,70 & 0,90 & 0,24 & 0,66 & 0,22 & 3,54 \\
\hline
\end{tabular}




\subsection{Methods - Design of experiments}

Various samples were prepared using different methodologies based on experimental design to predict the interaction component of the concrete mix. Experimental design is an important tool that can be used for product or process development and improvement [3]. In this study the effect of five control factors on the response, compressive strength of concrete, was investigated. All continuous variables were studied at 3 levels. Control factors levels used in this designed experiments were: $\%$ of cement mixing $(5 \%$, $20 \%, 30 \%)$, CFA $(0 \%, 15 \%, 30 \%)$, sand $(15 \%, 40 \%, 85 \%)$ CBA $(0 \%, 70 \%, 85 \%)$ and length of curing period/age (7, 14, 28 days). Table 2 below summarizes factors considered along with number of levels and level settings

Minitab 18.0 software is used create and design the DOE with orthogonal array method that resulted running in Table 3, summarizes the list of 27 sets of mixtures with 1 set replication that were prepared. Experimental results along with design matrix are tabulated. The order in which the experiments were performed was selected at random so that this design is completely randomized. The compressive strength of each of the samples was measured and evaluated for each case as the response variable.

Table 2. DOE factors

\begin{tabular}{lccc} 
DOE Factors & & & \\
\hline Factor & Level 1 & Level 2 & Level 3 \\
\hline$\%$ Cement & $5 \%$ & $20 \%$ & $30 \%$ \\
$\%$ CFA & $0 \%$ & $15 \%$ & $30 \%$ \\
$\%$ Sand & $15 \%$ & $40 \%$ & $85 \%$ \\
$\%$ CBA & $0 \%$ & $70 \%$ & $85 \%$ \\
Curing Period (Days) & 7 & 14 & 28 \\
\hline
\end{tabular}

Water content was adjusted until the required flow capability was achieved. The fresh mixture was then poured into paving mould of size $(21 \mathrm{~cm} \mathrm{x} 10.5 \mathrm{~cm} \times 6$ $\mathrm{cm})$, its top surface was leveled and kept covered with a wet cloth for two days in the laboratory condition after which the specimens were removed from the moulds and transferred to curing condition of $95 \%$ relative humidity at $22 \mathrm{C}$. The curing condition was achieved by keeping the paving block in partially water filled closed storage boxes and keeping the boxes in an air conditioned room as mentioned in [4].

Some nuisance (noise) factors were also identified, these are variables that probably have some effect on the response, but which are of little or no interest to the experimenter. They differ from held-constant factors in that they either cannot be held entirely constant, or they cannot be controlled at all. They include all composite batch-to-batch variation, and ambient temperature of the room and vibration of table while compaction and mixing. Other factors were predicted to exert some effect on the responses, but for the current study these factors are not of interest, so they have been held constant at a specified range. Examples of these factors include type of all composite, operator, water content in mix and cement to sand ratio. Table 4 outlines the noise factor and noise management strategy of each one. A standard Hobart mixer was used for the mixing process.

Table 3. Orthogonal array result

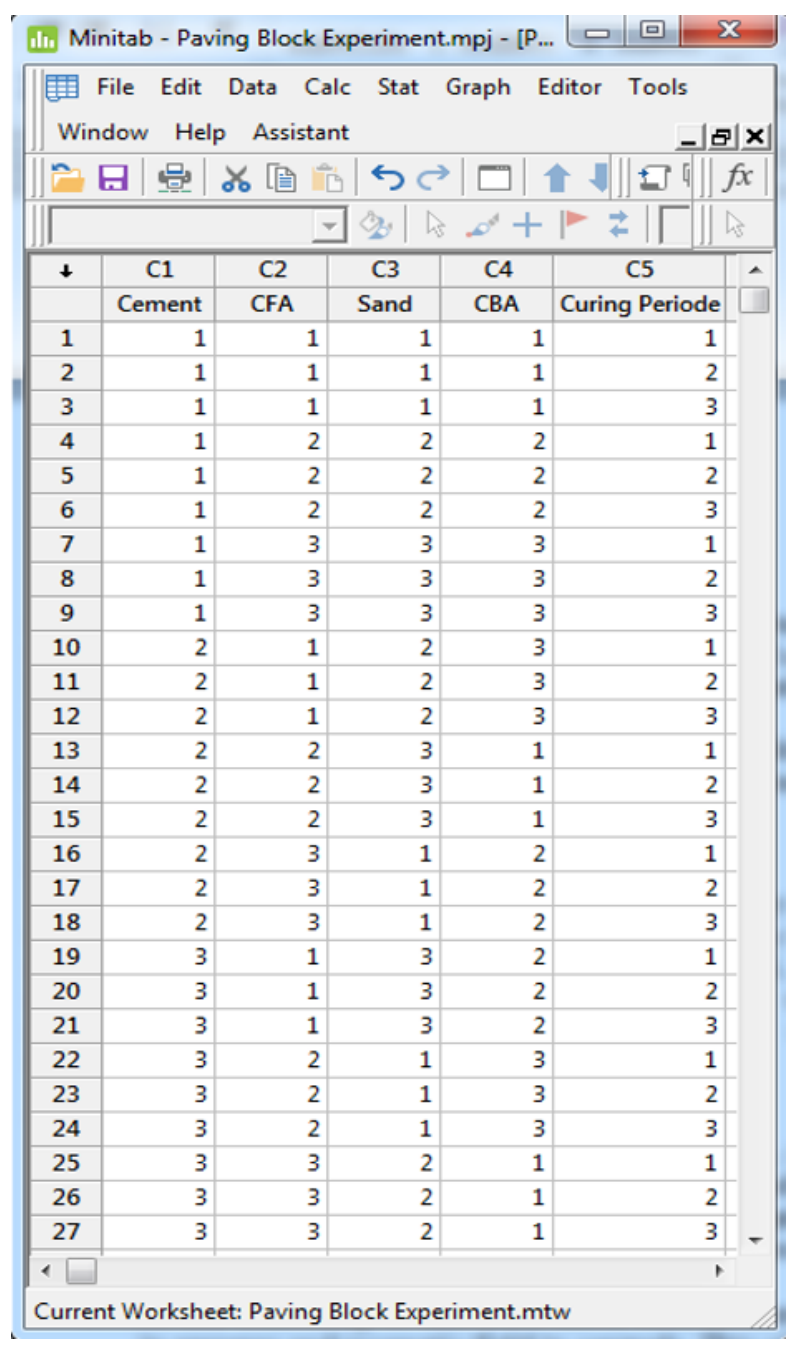

Table 4. Noise factor and management strategies

\begin{tabular}{ccc}
\hline Factors & $\begin{array}{c}\text { Anticipated } \\
\text { Effect }\end{array}$ & Noise Management Strategy \\
\hline Operator experience and skill & High & Use one experienced operator \\
Water content & High & Water in the mix was limited to 0.5 \\
Curing condition & High & Use same procedove for all experiment \\
Cement to sand ratio & High & kept at 1:3 \\
Batch to batch variation & Low & Block \& Randomization \\
Temperature of room effect & Low & Randomization \\
\hline
\end{tabular}

\section{Result and discussion}

\subsection{Compressive strength}

Results from the sets of experiments were investigated in more details for the compressive strength in Table 5. Fig. 1 shows the Pareto Chart of the factors affecting the 
compressive strength. Using Cement\% mixing and CBA\% have the highest effect which will be illustrated further when discussing effect of each factor. The interaction of the age/curing time with CFA\% and CBA\% also has a major effect. Other factors can be seen from the Pareto chart in descending order of influence. As stated earlier there is no interaction between wet mixing and sonication time since not all the sonication times can exist for sand mixing, similarly between wet mixing and whisking and other 3rd and 4th order interaction terms."

Fig. 2 illustrates the main effect plot of each of the factors studied. The effect of a factor is defined to be the change in response produced by a change in the level of the factor. Main effect is related to the primary factors of interest in the experiment. It can be seen that there is a non-linear relation between increasing the CFA \& CBA and the gain in sample compressive strength compared to the control, indicating that adding more CFA \& CBA does not necessarily result in a higher strength. As the age of the concrete increase, the compressive strength ratio also increases.

Table 5. Comprresive strength

\begin{tabular}{|c|c|c|c|c|c|c|c|c|c|}
\hline \multirow{2}{*}{$\begin{array}{l}\text { Exp } \\
\text { No. }\end{array}$} & \multirow{2}{*}{$\begin{array}{c}\text { Cement } \\
(\%)\end{array}$} & \multirow{2}{*}{$\begin{array}{l}\text { CFA } \\
(\%)\end{array}$} & \multirow{2}{*}{$\begin{array}{l}\text { Sand } \\
(\%)\end{array}$} & \multirow{2}{*}{$\begin{array}{l}\text { CBA } \\
(\%)\end{array}$} & \multirow{2}{*}{$\begin{array}{c}\text { Curing } \\
\text { Periods } \\
\text { (Days) }\end{array}$} & \multicolumn{2}{|c|}{$\begin{array}{c}\text { Compressire } \\
\text { Strength (MPa) }\end{array}$} & \multirow[t]{2}{*}{ Mean } & \multirow{2}{*}{$\begin{array}{c}\text { SNI } \\
\text { Standard }\end{array}$} \\
\hline & & & & & & $\mathrm{Rl}$ & $\mathrm{R} 2$ & & \\
\hline 1 & 25 & 0 & 75 & 0 & 7 & 4.13 & 5.52 & 4.83 & $\mathrm{~N} / \mathrm{A}$ \\
\hline 2 & 25 & 0 & 75 & 0 & 14 & 5.53 & 5.1 & 5.32 & $\mathrm{~N} / \mathrm{A}$ \\
\hline 3 & 25 & 0 & 75 & 0 & 28 & 8.51 & 8.75 & 8.63 & Quality D \\
\hline 4 & 8.33 & 25 & 66.67 & 0 & 7 & 4.89 & 6.12 & 5.51 & $\mathrm{~N} / \mathrm{A}$ \\
\hline 5 & 8.33 & 25 & 66.67 & 0 & 14 & 6.72 & 8.61 & 7.67 & $\mathrm{~N} / \mathrm{A}$ \\
\hline 6 & 8.33 & 25 & 66.67 & 0 & 28 & 8.76 & 8.27 & 8.52 & Quality D \\
\hline 7 & 2.45 & 14.63 & 41.46 & 41.46 & 7 & 17.12 & 19.04 & 18.08 & Quality B \\
\hline 8 & 2.45 & 14.63 & 41.46 & 41.46 & 14 & 22.45 & 23.87 & 23.16 & Quality B \\
\hline 9 & 2.45 & 14.63 & 41.46 & 41.46 & 28 & 27.13 & 26.52 & 26.83 & Quality B \\
\hline 10 & 13.8 & 0 & 27.58 & 58.62 & 7 & 21.35 & 21.53 & 21.44 & Quality B \\
\hline 11 & 13.8 & 0 & 27.58 & 58.62 & 14 & 27.04 & 29.11 & 28.08 & Quality B \\
\hline 12 & 13.8 & 0 & 27.58 & 58.62 & 28 & 35.56 & 37.08 & 36.32 & Quality A \\
\hline 13 & 16.67 & 12.5 & 70.83 & 0 & 7 & 20.56 & 20.44 & 20.50 & Quality B \\
\hline 14 & 16.67 & 12.5 & 70.83 & 0 & 14 & 25.65 & 26.13 & 25.89 & Quality B \\
\hline 15 & 16.67 & 12.5 & 70.83 & 0 & 28 & 33.34 & 35.07 & 34.21 & Quality B \\
\hline 16 & 14.82 & 22.22 & 11.11 & 51.85 & 7 & 10.49 & 9.94 & 10.22 & Quality D \\
\hline 17 & 14.82 & 22.22 & 11.11 & 51.85 & 14 & 14.78 & 15.42 & 15.10 & Quality C \\
\hline 18 & 14.82 & 22.22 & 11.11 & 51.85 & 28 & 18.97 & 21.24 & 20.11 & Quality B \\
\hline 19 & 16.23 & 0 & 45.94 & 37.83 & 7 & 15.82 & 17.1 & 16.46 & Quality C \\
\hline 20 & 16.23 & 0 & 45.94 & 37.83 & 14 & 19.34 & 20.67 & 20.01 & Quality B \\
\hline 21 & 16.23 & 0 & 45.94 & 37.83 & 28 & 24.45 & 25.66 & 25.06 & Quality B \\
\hline 22 & 20.68 & 10.34 & 10.34 & 58.64 & 7 & 19.22 & 19.51 & 19.37 & Quality B \\
\hline 23 & 20.68 & 10.34 & 10.34 & 58.64 & 14 & 27.67 & 26.41 & 27.04 & Quality B \\
\hline 24 & 20.68 & 10.34 & 10.34 & 58.64 & 28 & 32.54 & 34.42 & 33.48 & Quality B \\
\hline 25 & 30 & 30 & 40 & 0 & 7 & 5.66 & 5.95 & 5.81 & $\mathrm{~N} / \mathrm{A}$ \\
\hline 26 & 30 & 30 & 40 & 0 & 14 & 4.33 & 5.74 & 5.04 & $\mathrm{~N} / \mathrm{A}$ \\
\hline 27 & 30 & 30 & 40 & 0 & 28 & 7.56 & 8.63 & 8.10 & $\mathrm{~N} / \mathrm{A}$ \\
\hline 28 & 15 & 0 & 85 & 0 & 7 & 5.94 & 6.13 & 6.04 & $\mathrm{~N} / \mathrm{A}$ \\
\hline 29 & 15 & 0 & 85 & 0 & 14 & 7.47 & 8.01 & 7.74 & $\mathrm{~N} / \mathrm{A}$ \\
\hline 30 & 15 & 0 & 85 & 0 & 28 & 10.96 & 12.04 & 11.50 & Quality D \\
\hline
\end{tabular}

The best Compressive strength resulted from unproportional mixture with dominantly $\mathrm{CBA}$ is much higher than sand, and Cement higher than CFA (0\%) as per experiment no $10-12$. This is also influenced by other factors like curing period as illustrated in the interaction plot. This interaction was not captured by previous studies.

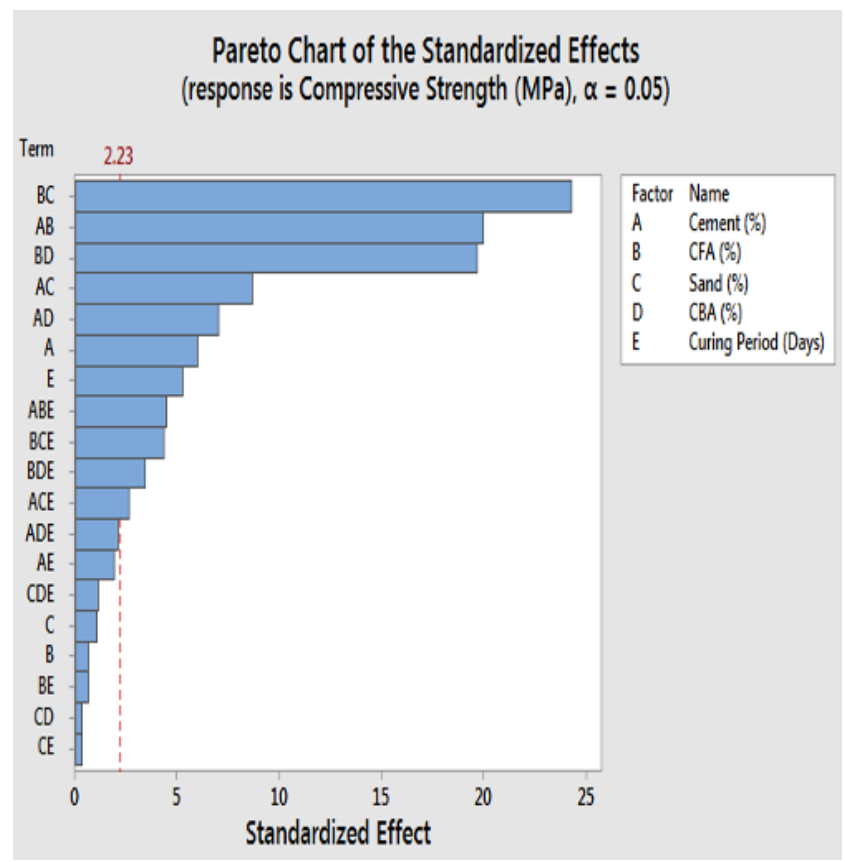

Fig. 1. Pareto chart of compressive strength.

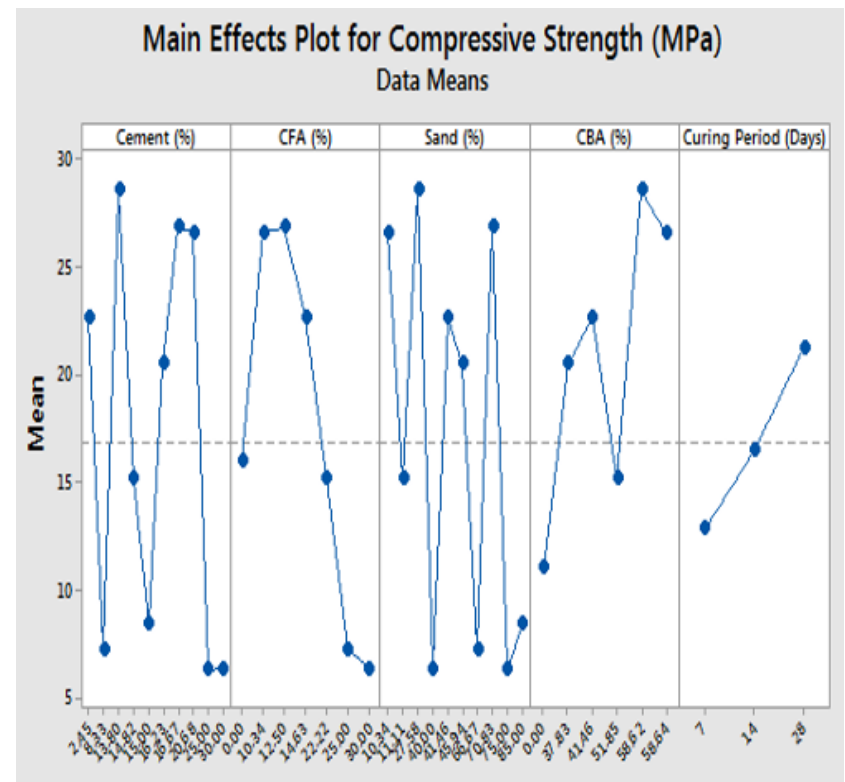

Fig. 2. Main effect plot for compessive strength.

The findings of this study were investigated further by considering the interaction plot for compressive strength as illustrated in Fig. 3. In some experiments the difference in response between the levels of one factor is not the same at all levels of the other factor. When this occurs there is an interaction between the factors. Any crossing indicates an interaction between variables. 


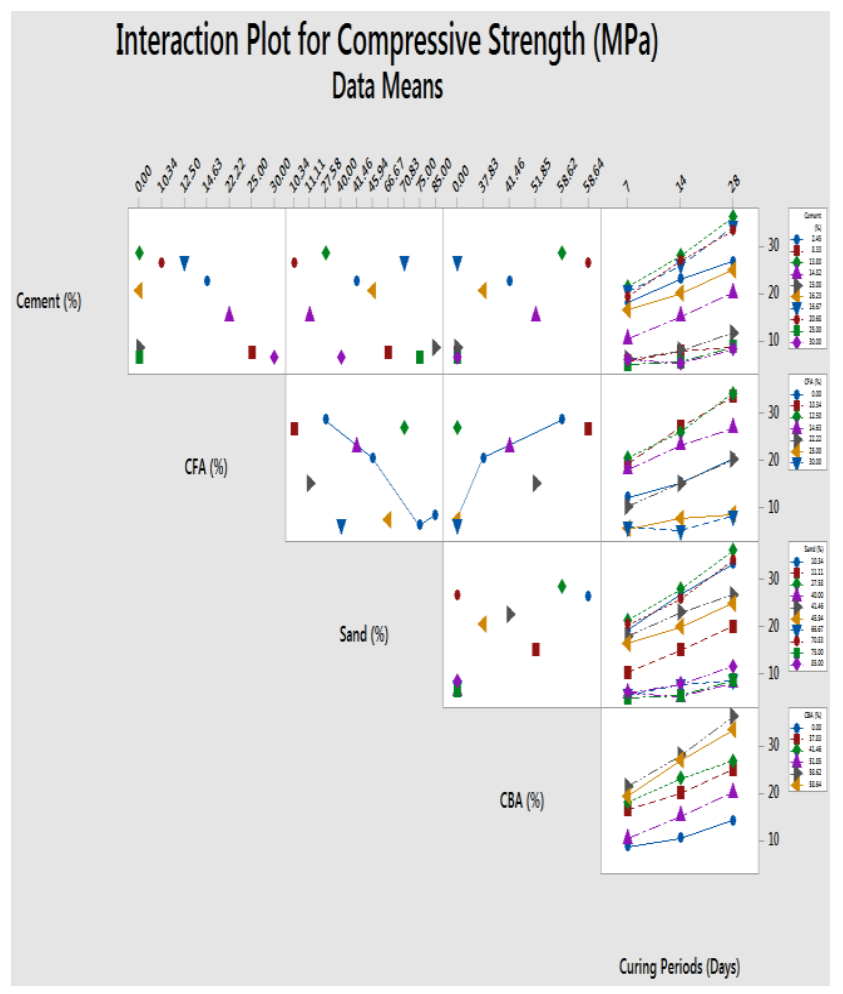

Fig. 3. Interaction plot for compessive strength.

To capture the above behavior, responses were modeled using response surface methodology as discussed earlier. Eq. (1) shows the model result for the compressive strength in terms of the process variables along with the goodness of fit. Quadratic terms, linear effects and interaction discussed earlier was captured through the model.

Compressive Strength ( $\mathrm{MPa})$

$28.158+4.833$ Cement $(\%)+0.335$ CFA $(\%)-$

0.528 Sand $(\%)$

+6.00 Curing Periods (Days)

+35.46 Cement $(\%) *$ CFA $(\%)$

+29.24 Cement $(\%) *$ Sand $(\%)$

+14.14 Cement $(\%) * \operatorname{CBA}(\%)$

+1.846 Cement $(\%) *$ Curing Periods (Days)

$+51.37 \mathrm{CFA}(\%)$

*Sand $(\%)+31.82$ CFA $(\%) *$ CBA $(\%)+0.394$ CFA $(\%)$

$*$ Curing Periods (Days) +0.39 Sand $(\%) *$ CBA $(\%)$ -

0.181 Sand (\%)

*Curing Periods (Days) + 9.49 Cement $(\%) *$ CFA $(\%)$

*Curing Periods (Days) + 10.68 Cement (\%)*Sand (\%)

*Curing Periods (Days) +5.12 Cement $(\%) *$ CBA $(\%)$

$*$ Curing Periods (Days) + 10.93 CFA $(\%) *$ Sand $(\%)$

$*$ Curing Periods (Days) +6.58 CFA $(\%) *$ CBA $(\%)$

*Curing Periods (Days) - 1.49 Sand $(\%) *$ CBA $(\%)$

*Curing Periods (Days)

...... (1)

$\mathrm{R} 2=99.44 \%$

With anova (Analysis of Variance) result is:
Analysis of Variance

\begin{tabular}{|c|c|c|c|c|c|}
\hline Source & DF & Adj SS & Adj MS & F-Value & P-Value \\
\hline Model & 19 & 2764.01 & 145.474 & 93.19 & 0.000 \\
\hline Linear & 4 & 105.71 & 26.427 & 16.93 & 0.000 \\
\hline Cement (\%) & 1 & 56.07 & 56.073 & 35.92 & 0.000 \\
\hline CFA (\%) & 1 & 0.67 & 0.668 & 0.43 & 0.528 \\
\hline Sand (\%) & 1 & 1.86 & 1.864 & 1.19 & 0.300 \\
\hline Curing Periods (Days) & 1 & 43.33 & 43.329 & 27.76 & 0.000 \\
\hline 2-Way Interactions & 9 & 1140.15 & 126.683 & 81.15 & 0.000 \\
\hline Cement (\%) ${ }^{*}$ CFA (\%) & 1 & 623.31 & 623.312 & 399.30 & 0.000 \\
\hline Cement (\%)*Sand (\%) & 1 & 117.07 & 117.073 & 75.00 & 0.000 \\
\hline Cement (\%)* CBA (\%) & 1 & 76.64 & 76.638 & 49.09 & 0.000 \\
\hline Cement (\%)*Curing Periods (Days) & 1 & 5.75 & 5.753 & 3.69 & 0.084 \\
\hline CFA $(\%)^{*}$ Sand $(\%)$ & 1 & 922.34 & 922.336 & 590.86 & 0.000 \\
\hline CFA $(\%)^{*} \mathrm{CBA}(\%)$ & 1 & 605.17 & 605.166 & 387.67 & 0.000 \\
\hline CFA (\%)*Curing Periods (Days) & 1 & 0.65 & 0.647 & 0.41 & 0.534 \\
\hline Sand $(\%)^{*} \mathrm{CBA}(\%)$ & 1 & 0.19 & 0.188 & 0.12 & 0.736 \\
\hline Sand (\%)*Curing Periods (Days) & 1 & 0.15 & 0.155 & 0.10 & 0.759 \\
\hline 3-Way Interactions & 6 & 46.40 & 7.733 & 4.95 & 0.013 \\
\hline Cement (\%)*CFA (\%)*Curing Periods (Days) & 1 & 31.41 & 31.405 & 20.12 & 0.001 \\
\hline Cement (\%)* Sand (\%)* Curing Periods (Days) & 1 & 10.99 & 10.991 & 7.04 & 0.024 \\
\hline Cement $(\%)^{*} \mathrm{CBA}(\%)^{*}$ Curing Periods (Days) & 1 & 7.08 & 7.084 & 4.54 & 0.059 \\
\hline CFA $(\%)^{*}$ Sand $(\%)^{*}$ Curing Periods (Days) & 1 & 29.39 & 29.388 & 18.83 & 0.001 \\
\hline CFA $(\%)^{*}$ CBA $(\%)^{*}$ Curing Periods (Days) & 1 & 18.23 & 18.225 & 11.68 & 0.007 \\
\hline Sand $(\%)^{*} \mathrm{CBA}(\%)^{*}$ Curing Periods (Days) & 1 & 1.89 & 1.889 & 1.21 & 0.297 \\
\hline Error & 10 & 15.61 & 1.561 & & \\
\hline Total & 29 & 2779.62 & & & \\
\hline
\end{tabular}

In the end, result of compressive strength will be compared with Standard National Indonesia (SNI). Mostly the result show that the compressive strength get the quality B of SNI with average compressive strength $20-35 \mathrm{MPa}$. For the best result showed by experiment No. 12 with $36.32 \mathrm{MPa}$ that the including quality A (average $40 \mathrm{MPa}$ ).

\subsection{Water absorption}

The first procedure is Dry the specimen in a ventilated oven at a temperature of $105^{\circ} \mathrm{C}$ to $115^{\circ} \mathrm{C}$ till it attains substantially constant mass. And then, cool the specimen to room temperature and obtain its weight (M1) specimen too warm to touch shall not be used for this purpose. Immerse completely dried specimen in clean water at a temperature of $27+2^{\circ} \mathrm{C}$ for 24 hours. In the end, remove the specimen and wipe out any traces of water with damp cloth and weigh the specimen after it has been removed from water (M2).

Water absorption, \% by mass, after 24 hours immersion in cold water in given by the formula Eq. (2) Shows,

$$
\mathrm{W}=\frac{\mathrm{M}_{2}-\mathrm{M}_{1}}{\mathrm{M}_{1}} \times 100
$$

The final result shows by Table.6 and Fig 4. Water absorption for the mixtures ranged between $1.98 \%$ and $10.72 \%$. The maximum water absorption for paving block under severe weather exposure is $17 \%$ whereas the same for paving block under moderate weather exposure is $22 \%$ [5]. Most of the paving block are found to have more water absorption values in this investigation. However these can be used in inner walls and situations of minimal weather exposure. Fig. 4 with implicit indicates the relationship between water absorption and $\mathrm{BA} / \mathrm{Cement}$ ratio. It can be observed that the water absorption values for the mixtures with BA:FA ratio of 1:5 are the lowest. This is because bottom ash is not a water absorber as the percentage of bottom ash water 
absorption is only $0.3-6.1 \%$ [5]. Yet fly ash is water absorbent material that increases the water absorption capacity of hardened matrix when it is used in the mix [6].

Table 6. Water absorpstion

\begin{tabular}{|c|c|c|c|c|c|c|c|c|c|c|c|}
\hline \multirow[t]{2}{*}{$\begin{array}{l}\text { Exp. } \\
\text { No }\end{array}$} & \multirow{2}{*}{$\begin{array}{c}\text { Cement } \\
(\%)\end{array}$} & \multirow{2}{*}{$\begin{array}{l}\text { CFA } \\
(\%)\end{array}$} & \multirow{2}{*}{$\begin{array}{l}\text { Sand } \\
(\%)\end{array}$} & \multirow{2}{*}{$\begin{array}{l}\text { CBA } \\
(\%)\end{array}$} & \multicolumn{2}{|c|}{$\begin{array}{c}\text { Wet Mass } \\
\text { (Kg) }\end{array}$} & \multirow{2}{*}{$\begin{array}{c}\begin{array}{c}\text { Dry Mass } \\
\text { (Kg) }\end{array} \\
\text { Rl }\end{array}$} & \multicolumn{2}{|c|}{$\begin{array}{c}\% \text { Water } \\
\text { Absorpstion }\end{array}$} & \multirow[t]{2}{*}{ Mean } & \multirow{2}{*}{$\begin{array}{c}\text { SNI } \\
\text { Standard }\end{array}$} \\
\hline & & & & & RI & $\mathrm{R} 2$ & & Rl & R2 & & \\
\hline 1 & 25 & 0 & 75 & 0 & 3.62 & 3.74 & 3.12 & 16.03 & 4.76 & 10.39 & $\mathrm{~N} / \mathrm{A}$ \\
\hline 2 & 8.33 & 25 & 66.67 & 0 & 3.42 & 3.48 & 3.14 & 8.92 & 9.43 & 9.18 & Quality D \\
\hline 3 & 2.45 & 14.63 & 41.46 & 41.46 & 3.56 & 3.65 & 3.44 & 3.49 & 3.99 & 3.74 & Quality B \\
\hline 4 & 13.8 & 0 & 27.58 & 58.62 & 3.62 & 3.58 & 3.54 & 2.26 & 1.70 & 1.98 & Quality A \\
\hline 5 & 16.67 & 12.5 & 70.83 & 0 & 3.68 & 3.7 & 3.48 & 5.75 & 5.41 & 5.58 & Quality B \\
\hline 6 & 14.82 & 22.22 & 11.11 & 51.85 & 3.68 & 3.71 & 3.41 & 7.92 & 8.48 & 8.20 & Quality D \\
\hline 7 & 16.23 & 0 & 45.94 & 37.83 & 3.62 & 3.66 & 3.38 & 7.10 & 7.65 & 7.37 & Quality C \\
\hline 8 & 20.68 & 10.34 & 10.34 & 58.64 & 3.41 & 3.38 & 3.32 & 2.71 & 3.05 & 2.88 & Quality A \\
\hline 9 & 30 & 30 & 40 & 0 & 3.63 & 3.64 & 3.36 & 8.04 & 13.40 & 10.72 & $\mathrm{~N} / \mathrm{A}$ \\
\hline 10 & 30 & 0 & 70 & 0 & 3.68 & 3.66 & 3.39 & 8.55 & 6.71 & 7.63 & Quality C \\
\hline
\end{tabular}

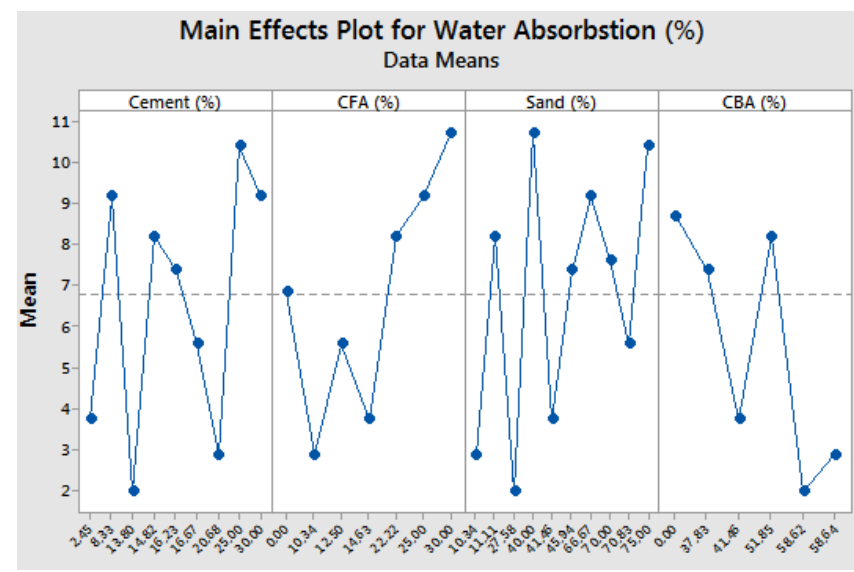

Fig. 4. Main effect plot for water absorption.

\section{Conclusion}

Mixed results in literature about the influence of CBA \& CFA on the mixture properties of paving block are very well justified since varying the procedure significantly affects the result. Depending on the procedure adopted, CBA \& CFA can be effectively dispersed in the mix resulting in higher strength. This research compared the degree of variability that exists in concrete blocks from CBA \& CFA dispersions when prepared using different protocols for the same cement to water ratio. Results clearly illustrates that for the purpose of data comparability, there is a need to provide the exact details of all steps involved in a dispersion protocol and an optimum protocol can be standardized.

From the data above, results of Compressive Strength \& Water Absorptions show that experiment No.12 with the mixtures component Cement $13.8 \%$, CFA 0\%, Sand $27.58 \%$, and CBA $58.62 \%$ in curing period 28 days give the best result and recommendation for production of paving block, of course also with concern the noise factor, but for the both influence composition CFA \& CBA that showed exp. 24 with Cement 20.68\%, CFA 10.34\%, Sand $10.34 \%$, and CBA $58.64 \%$ in 28 days. In the case experiment for industrial manufacturer, Orthogonal Array is very helpful because the company can reduce time and also reduce cost for to get the best result.

For the future work of the experiment, next researcher can mixture with the other sand types, add addictive fluid to composite and resetting DoE factor to get the best result. Researcher too can verify result of experiment with SEM (Scanning Electron Microscope)

\section{Acknlowledgement}

Authors wish to acknowledge the Department of Industrial Engineering of University Of Indonesia.

\section{References}

1. R. Siddique,. "Utilization of Coal Combustion byProducts in Sustainable Construction Materials. Resources. Conservation and Recycling". (2010). 54.pp 1060- 1066.

2. M. Rafieizonooz, J. Mirza, M.R. Salim, M.W. Hussin, E.Khankhaje. "Investigation of Coal Bottom Ash and Fly Ash in Concrete as Replacement for Sand and Cement. Construction and Building Materials". (2016) 116. 15-24.

3. Douglas Montgomery, Design and Analysis of Experiments, John Wiley \& Sons,NJ, 2009.

4. Hashim Abdul Razak, Sivakumar Naganathan, Siti Nadzriah Abdul Hamid, Performance appraisal of industrial waste incineration bottom ash as controlled low-strength material, J. Hazard. Mater. 172 (2009) 862-867

5. Craig H. Benson, Sabrina Bradshaw, User Guideline for Coal Bottom Ash and Boiler Slag in Green Infrastructure Construction. Recycled Materials Resource Centre, University of Wisconsin Madison, USA, 2011.

6. S. Naganathan, N. Subramaniam, K.N. Mustapha, Development of bricks from thermal power plant bottom ash and fly ash, Asian J. Civil Eng. 1 (2012) 275- 287. M. Young, The Technical Writer's Handbook. Mill Valley, CA: University Science, 1989.

7. Badan Standar Nasional. (1996). Bata beton (Paving block). SNI. 03-0691-1996.

8. Concrete Manufacturers Association (2009). Concrete Block Paving, Book 1- Introduction. Midrand: Author. Februari 5, 2017. www.cma.org.za

9. Concrete Masonry Association of Australia. "Permeable Interlocking Concrete Pavements Design and Construction Guide". Artarmon NSW, Australia: Author, 2010

10. Gabriel, D.S. "How to Increase Plastic Waste Acceptance for Mechanical Recycling: An Introduction to Material Value Conservation and Its Phenomenon". Key Engineering Materials. (2016). 705. 362-367.

11. Interlocking Concrete Pavement Institute. (2003). "Structural Design of Interlocking Concrete Pavement for Roads and Parking Lots". Tech spec No. 4. Washington, DC: Author. 14 Mei, 2017. http://www.panablock.com/content_images/Tech\%2 0Spec\%204.pdf

12. R. Siddique. "Utilization of Coal Combustion byProducts in Sustainable Construction Materials. 
Resources. Conservation and Recycling”. (2010). 54. 1060- 1066

13. R. Siddique. "Compressive Strength, Water Absorption, Sorptivity, Abrasion Resistance and Permeability of Self-Compacting Concrete
Containing Coal Bottom Ash". Construction and Building Materials. (2013). 47. 1444-1450.

14. M. Singh \& R. Siddique,). Effect of Coal Bottom Ash as Partial Replacement of Sand on Properties of Concrete. Resources. Conservation and Recycling. (2013). 72. 20-32. 